\title{
Donor Hemovigilance Programme in managing Blood Transfusion Needs:Complications of Whole Blood Donation
}

\author{
Mangwana $\mathrm{S}^{1}$ \\ ${ }^{I}$ Department of Blood Transfusion Services, Sri Balaji Action Medical Institute, New Delhi, India
}

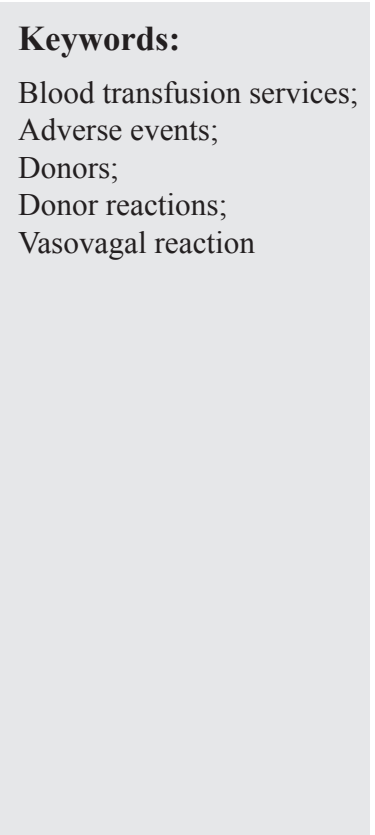

\begin{abstract}
Background: Hemovigilance like quality systems and audits have become an integral part of Blood Transfusion Services in the developed countries and has contributed greatly to its development. Hemovigilance begins with donors and must enable the collection of information on reactions occurring during the donation of blood, selections of donors and to prevent such incidents. The aim of study was to help identify the trends of adverse events, occurring in blood donors at a tertiary-care hospital, to recommend best practices to improve donor care and safety
\end{abstract}

Materials and Methods: This record-based study was conducted on all adverse events related to allogenic whole blood donations performed over 24 months. All whole blood donations were analyzed. All adverse events occurring during or at the end of the donation were noted using a standardized format and analyzed determining significance at $\mathrm{p}<0.05$.

Results: Overall rate was $0.3 \%$ with vasovagal reactions constituting $82 \%$, and $18 \%$ mild syncopal reactions $(p<0.001)$. Immediate vasovagal reaction with injury was very rare $(0.007 \%)$. Vasovagal reactions showed a significant association with young age, female gender, first time donation status. Mean age of persons recording adverse effects was $30.23 \pm 7.49$ years as compared to those without adverse effects, $31.14 \pm 8.56$ years.

Conclusion: Donor safety is an essential perquisite to increase voluntary blood donation. AE analysis helps in identifying the blood donors at risk of AE, applying appropriate motivational strategies, predonation counseling, care during and after donation, developing guidelines and hemovigilance programme in countries with limited resources.

\section{INTRODUCTION}

Hemovigilance like quality systems and audits have become an integral part of Blood Transfusion Service (BTS) in the developed countries and have contributed greatly to the

\section{Correspondence:}

Dr. Sadhana Mangwana, MD

Department of Blood Transfusion Services, Sri Balaji Action Medical

Institute, New Delhi, India

Email: sadhanamangwana@yahoo.co.in development of Blood Transfusion Services. The goal of hemovigilance is to identify and prevent occurrence / recurrence of transfusion related unwanted events, in order to increase the safety, efficacy and efficiency of blood transfusion, covering all activities of blood transfusion chain from donors to recipients. However, developing countries are still grappling with donor recruitment, retention and efforts towards sufficiency and safety of blood supply. 
Tools to help improve the safety of blood supply include -

1. Clinical (Transfusion) guidelines

2. Audit systems to monitor adherence to the guidelines as well as effects of guidelines.

3. Hemovigilance programme which monitors the entire blood supply chain, develop measures and solutions to the problems anywhere along the chain that can threaten the safety of component supply and monitors the implementation of these corrective actions.

Hemovigilance begins with donors and donations of blood and must enable the collection of information on reactions occurring during the donation of blood, selections of donors and to prevent the occurrence or recurrence of such incidents.

Whole blood donation is generally considered to be safe and uncomplicated procedure but occasionally donors experience adverse reactions of variable severity during or at the end of collection. Despite complications rates of blood donations being relatively low, donor complications are an important problem, not only for donors but also for the transfusion medicine in general, as some complications may negatively affect donor recruitment and retention.

There have been innumerable studies and articles in the literature on the recording and management of adverse events related to transfusion of blood component to the patients, data on donor adverse events is primarily from western studies. ${ }^{1-10}$ In order to estimate the frequency and type of adverse events occurring in whole blood donors at a tertiary-care hospital, to disseminate the findings, to develop evidence-based medicine and to introduce new and/or existing policies for monitoring blood safety and to bring uniformity in hemovigilance system, this recordbased study was conducted.

\section{MATERIALS AND METHODS}

Record-based study was conducted on all adverse events related to allogenic whole blood donations performed over 24 months from January 2010 to December 2011. Criteria for the selection of whole blood donors were in accordance with rules laid down in Drugs and Cosmetic Act, Ministry Of Health and Family Welfare, Govt. of India. ${ }^{11}$ Blood donors must be 18 to 65 years old and in good health. All donations were performed using 16 gauze needles from vein in the antecubital area after maintaining strict asepsis of venipuncture site.

It is important to react swiftly to initial complaints of giddiness, light headedness, pallor by donor by stopping the donation immediately and raising the legs and lowering of head end of donor couch (Anti-shock position) as pallor, sweating, giddiness are harbingers of severe vasovagal reactions which could be prevented by taking corrective measures right at the onset of symptoms.

\section{Adverse Events (AE)}

Donor adverse reactions were classified into local symptoms, generalized symptoms, complications related to Apheresis and others into 13 categories ${ }^{12}$. In order to create database, data was collected on the form designed as per guidelines by American Red Cross Hemovigilance Programme: ${ }^{1}$

Presyncopal symptoms included pallor, sweating or lightheadedness without loss of consciousness.

Syncopal type of complications were classified as:

Minor - transient loss of consciousness lasting for $<$ 1 minute

Major - prolonged loss of consciousness for $>1$ minute or complicated by loss of bladder/ bowel control, seizures or convulsions

Local adverse events- hematomas which can be small $\left(<25.8 \mathrm{~mm}^{2}\right)$ or large $\left(>25.8 \mathrm{~mm}^{2}\right)$, bruises, infiltration, allergic reactions and a tingling / burning sensations.

Once the donor recovered from $\mathrm{AE}$, a detailed report was filled by phlebotomist. For delayed reactions, the donor was advised to be in touch with designated staff of blood transfusion services.

This study was approved by the Institutional Ethics Committee.

Statistical Analysis: The data has been summarized through frequency distributions and contingency tables along with suitable graphs. Statistical analysis was performed with Mann-Whitney and Chi-square/Fisher's Exact test using SPSS version 15.0 software determining significance at $\mathrm{p}<0.05$.

\section{RESULTS}

During the 24 months period, blood centre at a Tertiarycare hospital performed 14,600 donations of which 13,015 $(89.14 \%)$ were whole blood donations $(350 \mathrm{ml} / 450 \mathrm{ml})$ while $1585(10.86 \%)$ were SDP donations.

The 5907 (45.39\%) donations were made by first time donors and $7108(54.61 \%)$ by repeat donors ( $\mathrm{p}$ value $<0.001)$. There were $247(1.90 \%)$ voluntary donors and $12,768(98.10 \%)$ replacement donors ( $\mathrm{p}$ value $<0.001)$.

Out of 13,015 whole blood donations 12,169 (96.96\%) were made by male donors and $396(3.04 \%)$ by female donors. ( $p$ 
Table 1: Age and Sex Wise Comparison of Donations And Adverse Events

\begin{tabular}{|c|c|c|c|c|c|c|c|}
\hline \multirow{2}{*}{ Age Range (yrs) } & \multicolumn{3}{|c|}{ DONATIONS } & \multicolumn{3}{|c|}{ ADVERSE EVENTS } & \multirow{2}{*}{$\begin{array}{l}\text { AE\% Vs } \\
\text { Donation }\end{array}$} \\
\hline & Females & Males & Total & Females & Males & Total & \\
\hline $18-25$ & $75(1.85)$ & 3979(98.15) & $4054(31.15)$ & 1 & 11 & $12(30.77)$ & 0.30 \\
\hline $26-35$ & $124(2.33)$ & 5204(97.67) & $5328(40.94)$ & 0 & 16 & $16(41.02)$ & 0.30 \\
\hline $36-45$ & $133(4.95)$ & $2552(95.05)$ & $2685(20.63)$ & 0 & 10 & $10(25.65)$ & 0.37 \\
\hline $46-55$ & $55(6.54)$ & 786(93.46) & $841(6.46)$ & 1 & 0 & $1(2.56)$ & 0.12 \\
\hline 56- 65 & $9(8.41)^{*}$ & 98(91.59) & $107(0.82)$ & 0 & 0 & 0 & 0 \\
\hline Grand Total & $396(3.04)$ & $12619(96.96)^{*}$ & $13015(100)$ & $2(0.50)^{*}$ & $37(0.29)$ & $39(100)$ & 0.30 \\
\hline
\end{tabular}

Note - Figures in parentheses indicate percentages, ${ }^{*} \mathrm{p}$ value $<0.001, \dagger$ odd ratio $=1.726(0.422,7.063)$

value $<0.001)$ (Table 1).

Mean age of donors was $31.14 \pm 8.56$ years with a range of 18 to 65 years. Mean age of male donors was $31.02 \pm 8.49$ years and female donors $35.02 \pm 9.74$ years ( $\mathrm{p}$ value $<0.001$, Mann-Whitney test)

No. of donations in various age groups is significantly associated with gender. Hence, in the age group categorization, highest donations $(5328,40.94 \%)$ was made in the age range of 26-35 years followed by $18-25$ years age group $(4054,31.15 \%)$ and $36-45$ years age groups $(2685,20.63 \%)$. The age group $46-55$ and $56-65$ years had the lowest donations as $6.46 \%(841)$ and $0.82 \%$ (107) respectively. In the different age groups, males were the predominant donors ranging from $91.40 \%$ to $98.15 \%$ while the maximum females $(9.08 \%)$ were in the age group of 55 65 year. (p value $<0.001$; Table 1 ).

Out of 13,015 whole blood donations, donor adverse events were noted in 39 donors amounting to an overall incidence of $0.30 \%$. Out of the female donors, $0.50 \%$ females developed adverse events while $0.29 \%$ of male donors developed adverse events ( $p$ value- 0.448 ), Odds Ratio in favor of females recording adverse event is 1.726 $(0.422,7.063$; Table 1).

Reaction percentage within the age groups were highest $(0.37 \%)$ in $36-45$ years followed by $26-35$ years and $18-25$ years age groups $(0.30 \%$ each) while the lowest in $46-55$ years age groups as $0.12 \%$. There was no adverse event in 56-65 years age group (Table 1).The mean age of persons recording adverse events is $30.23 \pm 7.49$ years as compared to those without adverse events, $31.14 \pm 8.56$ years ( $p$ value-0.507, Mann-Whitney test) .

We tried to analyze the incidence of adverse events within the particular $\mathrm{ABO} \mathrm{Rh}$ group donations and found that highest percentage of adverse events $(0.87 \%)$ was in ' $\mathrm{O}$ ' Negative donors followed by 'B' Negative donors $(0.33 \%)$ while there were no adverse events in ' $A$ ' negative and 'AB' Negative donors. The type of blood groups reporting adverse events are not associated with gender and age (Fisher's Exact Test $\mathrm{p}$ value- $0.772 \& 0.836$ respectively).
Frequency of $\mathrm{AE}$ within various blood groups $\mathrm{AE}$ was highest in ' $\mathrm{B}$ ' Positive followed ' $\mathrm{O}$ ' Positive, 'A' Positive, 'AB' Positive, 'O' Negative, 'B' Negative. There was no adverse events in female Rh Negative donors (fig. 1).

Of all the adverse events, 59\% (23/39) adverse events were observed in first-time donors while 41\% (16/39) were in repeat donors. The frequency of adverse events in firsttime donors in different age groups is shown in figure $2(p$ value-0.113). The number of adverse events in first time/ repeat donors is not significantly associated with age distribution ( $p$ value-0.134, Fisher's Exact test).

Majority of adverse events $(82 \%, 32 / 39)$ were systemic, generalized symptoms (i.e. mild vasovagal reactions) while $18 \%(7 / 39)$ donors showed moderate vasovagal reactions ( $p$ value $<0.001)$. They affected $0.3 \%$ of the donors (39/13015). Immediate vasovagal reaction with injury was very rare; $0.007 \%(01 / 13015)$. Forty four percent (17/39) donors with adverse events were able to complete the donation. Eighty two percent (32/39) of all adverse reactions occurred in phlebotomy room. None of the donor with adverse event necessitated the hospitalization.

\section{DISCUSSION}

The aim of this study was to estimate the frequency and type of adverse events occurring in whole blood donors so that appropriate actions can be taken through appropriate educational processes to prevent occurrence and recurrences of these incidences and sufficient and safe blood supply can be maintained by ensuring safety and well-being of the donors. Although whole blood donation is considered to be safe, reports in the medical literature about the frequency of adverse events during donation show broad heterogeneity. ${ }^{6,79}$

Donation-related adverse events were recorded according to standardized criteria. However, a classification of complications has been implemented in accordance with Standards for Surveillance of Complications Related to Blood Donations. ${ }^{12}$

In our study, $0.3 \%$ of all whole blood donations were 


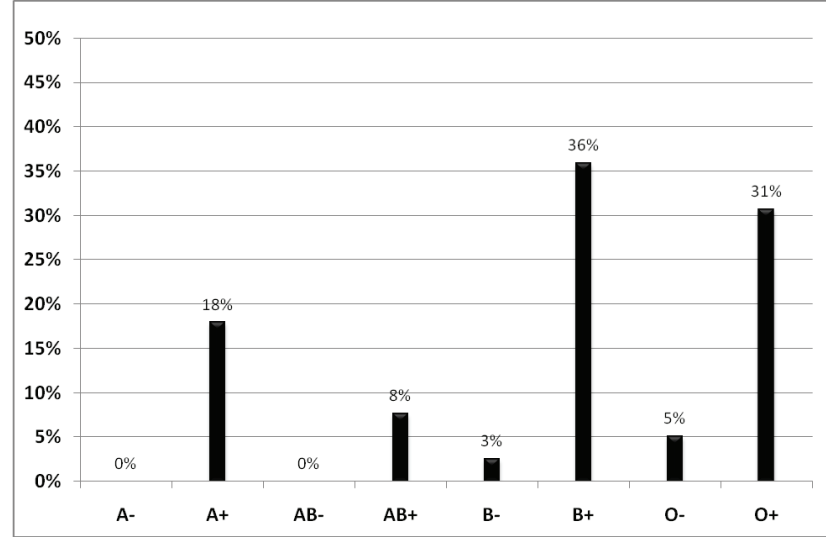

Figure 1: Group Wise Adverse Events

complicated by an adverse event. This is in accordance with various studies conducted all over the world in which the rate of adverse events associated with donations ranged from $0.3 \%$ to $3.8 \% \%^{2-10,13,14}$ Variations may result due to differences in donor demography, behavior of collection staff and methodology used to obtain information regarding adverse events from donor.

As part of our study, we tried to analyze the various patterns and found that highest adverse events occurred in the age group of 26-35 years ( $0.37 \%)$. Young age, female gender and first time donation status were associated with significantly higher reaction prevalence. ${ }^{5,14}$ There was significant drop in reaction prevalence after the age of 36 years. Mean age of donors recording adverse events is $30.23 \pm 7.49$ years compared with mean age of donors without adverse events $31.14 \pm 8.56$ years ( $\mathrm{p}$ value -0.507 ). A study by France postulated that baroreceptor sensitivity is decreased in healthy young individuals when they are physically or psychologically stressed. ${ }^{15}$ With increasing age, body becomes more stable hemodynamically. Also the young donors were more apprehensive to the pain of phlebotomy.

Female donors showed $0.50 \%$ incidence of adverse events against $0.29 \%$ incidence in male donors. Female donors, both voluntary \& replacement, had significantly higher prevalence similar to other studies. ${ }^{14}$ Repeat donation status lowered the chance of adverse events as compared to first time donations but the number of adverse events in first time / repeat donors did not show any association with age distribution ( $\mathrm{p}$ value -0.134 ).

Amongst different blood group donations ' $O$ ' negative donors showed the highest incidence of AE $0.87 \%$ with no adverse events in ' $\mathrm{A}$ ' negative and 'AB' negative donors.

The most common systemic and phlebotomy related complications (i.e. Pre-syncope, small hematoma), although uncomfortable for the donor, are medically inconsequential. The significance of these minor complications, however, lies primarily in the observation that any complication, even a minor one, reduces the chances of donor retention

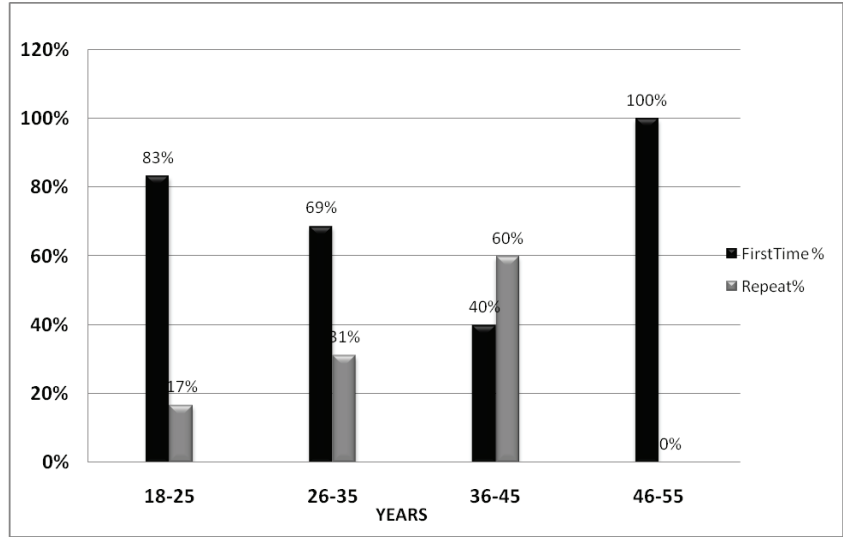

Figure 2: AE in First Time and Repeat Donors

or repeat donation. In addition, minor complications may be an indirect measure of more serious complications, although this is difficult to assess because of infrequent occurrence.

Mild vasovagal reactions, which include giddiness, sweating or light headedness without loss of consciousness, accounted for $82 \%$ of all adverse events $(0.24 \%$ of total donations) while moderate vasovagal reactions accounted for $18 \%$ of all adverse events $(0.05 \%$ of total donations) which is consistent with data from previous studies. ${ }^{2,13}$

We found a very low incidence $(0.007 \%$ of total donations) of vasovagal reaction- immediate with injury but not necessitating hospitalization of the donor or administration of intravenous fluid which is in accordance with results of other authors ${ }^{2,3,13}$ who categorized such adverse events as severe reactions (major syncopal reactions).

Donor safety is an essential perquisite to increase voluntary blood donation. One of the key objectives of our national blood policy is to achieve $100 \%$ voluntary blood donation, ${ }^{16}$ The present national average being 61\%.Adverse events analysis helps in identifying the blood donors at risk of donor reactions, applying appropriate motivational strategies, pre-donation counseling, care during and after donation, developing guidelines and hemovigilance programme in countries with limited resources if a step-up approach is used. As per WHO Global Database Report on Blood Safety, ${ }^{17}$ the national hemovigilance system is present in $42(40 \%)$ of the 105 reporting countries with 24 countries $(23 \%)$ being in process of development of such a system. $39(37 \%)$ counties do not have a national hemovigilance system. Among the Asian counties a well established hemovigilance system is lacking and there is paucity of data on hemovigilance except in Japan. ${ }^{18}$ In India, a national blood system has been launched on December10, 2012. ${ }^{19}$ This programme is an integral part of Pharmacovigilance programme of India.

\section{CONCLUSION}

In order to have a well organized hemovigilance system 
in developing countries like India, a comprehensive approach is required. A streamlined mechanism for data collection using standardized tools at hospital level and good coordination at national level can bring up effective hemovigilance system in a country. The data from a well functioning hemovigilance system can be used as quality indicator for monitoring blood safety and also contribute significantly to evidence-based medicine as well as help to introduce new and /or access the existing blood policies. There is need to strengthen and to bring uniformity in the hemovigilance system globally.

\section{REFERENCES}

1. Eder AF, DyBA, Kennedy JA et al. The American Red cross Donor Hemovigilance Programme, Complications of donation: Transfusion 2006;46:2037-42.

2. Crocco I, Franchini M, Garozzo G et al. Adverse reactions in Blood and Apheresis Donors: experience from two Italian Transfusion centres. Blood transfuse 2009;7:35-8.

3. Crocco A, D'Elia. Adverse reactions during voluntary donation of blood and / or blood components. A stastical -epidermiology study. Blood Transfus 2007;5:143-52.

4. Sorensen B S, Johnsen S, Jorgensen J. Complications related to blood donation: a population-based study. Vox Sang 2008;94:132-37.

5. Eder AF, Hillyer $\mathrm{CD}$, Dy $\mathrm{BA}$ et al. Adverse reactions to allergenic whole blood donation by 16- and 17- Year olds. JAMA 2008;299:2279-86

6. Garozzo G,Crocco I, Giussani B et al. Adverse reactions to blood donations: the READ project. Blood Transfus 2010;8:49-62.

7. Witibank TB, Giordano GF, Kamel $\mathrm{H}$ et al. Faint and pre faint reactions in whole blood donors: an analysis of predonation measurements and their predictive value. Transfusion 2008,48:17991808 .

8. Goncalez TT, Sabino EC, Schlumf KS et al. Vasovagal reactions in whole blood donors at three. REDS- II blood centers in Brazil. Transfusion. 2011; doi: 10.1111j. 1537-2995.
9. Newman BH, Pichette S, Pichette D et al. Adverse effects in blood donors after whole blood donation: a study of 1000 blood donors interviewed 3 weeks after whole- blood donation. Transfusion 2003;43:598-603.

10. Eder AF, DyBA, Kennedy JM et al. The American Red Cross donor Hemovigilance program: Complications of blood donation reported in 2006. Transfusion 2008;48:1809-19.

11. Drugs and Cosmetic Act 1940. 16th ed. Lucknow: Eastern Book Company; 2003. 279-303pp.

12. Common Working Group on Complications Related to Blood Donation DOCO).Standard for Surveillance of Complications Related to Blood Donation.2008. Available at :http://www.basg. gv.at/upload/media/110207__ Standard SurveillanceDOCO.pdf "Accessed on 31/08/2012."

13. Pathak C, Pujani M, Pahuja S,. Jain M. Adverse reactions in whole blood donors: an Indian scenario. Blood Transfuse 2011;9:46-9.

14. Agnihotri N, Marwaha N, Sharma RR. Analysis of adverse events and predisposing factors in voluntary and replacement whole blood donors: A study from north India. Asian J Transfus Sci 2012;6:15560.

15. France C. Baroreflex sensitivity during noxious stimulation in vasovagal reactors to blood donation. Int J Psychophysiol $1995 ; 19: 13-22$

16. National Blood Policy.Objective1: To reiterate firmly the Govt. commitment to provide safe and adequate quantity of blood, blood components and blood products. National AIDS Control Organization. Ministry of Health and Family Welfare. Govt. of India; 2007. p2-3 Available at :http://www.nacoonline.org/\%20upload/ final $\% 20$ publications/blood\%20safety / \% Blood\% 20policy.pdf. "Accessed on 31/08/2012".

17. Dhingra N. Hemovigilance in Developing Countries. Blood Transfusion Safety, World Health Organization, Geneva. Available from: http://www.blood transfusion.it/articoli/47/en/Doi\%200010. pdf. "Accessed on 15/01/2013".

18. Jain A, Kaur R. Hemovigilance and Blood Safety. Asian J. Transfus Sci 2012;6:137-8.

19. Bisht A, Singh S, Marwah N. Hemovigilance Programme-India. Asian J. Transfus sci [serial online]2013;7:73-4. Available from: http://ajts. org/text.asp?2013/7/1/73/106744 "Accessed on 16/03/2013". 